\title{
Proapoptotic Sulindac Analog CP-461
}

National Cancer Institute

\section{Source}

National Cancer Institute. Proapoptotic Sulindac Analog CP-461. NCI Thesaurus. Code C133019.

An orally bioavailable second-generation selective apoptotic antineoplastic drug (SAAND) and analog of the nonsteroidal anti-inflammatory drug (NSAID) sulindac, with potential pro-apoptotic and antineoplastic activities. Upon administration, CP-461 specifically binds to and blocks the activity of cyclic guanosine monophosphate-phosphodiesterase (cGMP-PDE), an enzyme that inhibits the normal apoptosis signal pathway. Inhibition of CGMP-PDE permits the apoptotic signal pathway to proceed unopposed, resulting in apoptotic cell death. cGMP-PDE is overexpressed in a variety of cancer cell types; therefore, CP-461 selectively induces apoptosis in cancer cells, with minimal or no effect in healthy cells. 